\title{
Worm in the Throat: Hamartoma Larynx
}

\author{
${ }^{1}$ Sudarshan Loka Reddy, ${ }^{2}$ Nagendra Kadapa
}

\begin{abstract}
Hamartomas of larynx are rare benign lesions which can be a rare cause for respiratory obstruction. This report highlights the case of a young female who presented with foreign body sensation and worm-like mass in throat of 10 years duration. On videolaryngoscopy, a pinkish polypoidal worm like mass was seen arising from the right side of epiglottis on the laryngeal surface. Endoscopic guided excision with cautery was done and the mass revealed hamartoma on histopathology.
\end{abstract}

Keywords: Hamartoma, Videolaryngoscopy, Epiglottis.

How to cite this article: Reddy SL, Kadapa N. Worm in the Throat: Hamartoma Larynx. Int J Phonosurg Laryngol 2014;4(1):33-35.

\section{Source of support: Nil}

\section{Conflict of interest: None}

\section{INTRODUCTION}

Albrecht introduced the term 'hamartoma' in 1904, ${ }^{1}$ and distinguished between true neoplasms and tumor like lesions. In 1991, the World Health Organization defined hamartomas as anomalies characterized by the formation of a tumor like mass composed of identical mature cellular tissue elements that are normally present where the mass is found but that occur in abnormal proportions or patterns. ${ }^{2}$ It may arise from any of the germ layers and does not metastasize. Although hamartomas have been described as occurring throughout the body, they remain a rare finding in the head and neck region. Hamartoma may present as a single lesion or in terms of a multiple hamartoma syndrome. ${ }^{3,4}$ They usually involve the lungs or organs in the abdominal cavity. The lesion usually presents as a submucosal mass with ill-defined margins. Microscopically, the tissue shows mesenchymal elements, either in isolation or mixed loosely with epithelial structures in a disorganized architectural pattern. Hamartomas are

\footnotetext{
${ }^{1}$ Associate Professor, ${ }^{2}$ Registrar

${ }^{1}$ Department of ENT, Osmania Medical College, Hyderabad Telangana, India

${ }^{2}$ Department of Surgical Oncology, Basavatarakam IndoAmerican Cancer Hospital and Research Institute, Hyderabad Telangana, India

Corresponding Author: Nagendra Kadapa, Registrar, Department of Surgical Oncology, Basavatarakam Indo-American Cancer Hospital and Research Institute, Hyderabad, Telangana India, e-mail: drnagendrak@gmail.com
}

identified according to the preponderance of a particular structure (cartilage, fat, neural structures or fibromuscular tissue). Mesenchymal hamartomas, which contain only mesodermal elements, are much more common than epithelial or glandular hamartomas, which show a mixture with mesodermal element. ${ }^{5}$

We report a case with the unusual presentation of wormlike mass in throat that was consistent with laryngeal hamartoma. The clinicopathologic features and treatment, are discussed along with review of relevant literature.

\section{CASE REPORT}

A27-year-old female presented to our outpatient department with history of foreign body sensation and worm like mass in the throat (Fig. 1) since 10 years. There was difficulty in breathing since 3 days prior to admission. On videolaryngoscopy, a smooth, shiny elongated pinkish worm-like mass was seen arising from the right side of the epiglottis on its laryngeal surface. The mass was freely mobile at one end and attached to the epiglottis at the other end (Fig. 2). The examination of nose and ears was normal. A provisional diagnosis of hamartomatous polyp and leiomyoma was thought of.

The case was posted for endoscopic guided excision of the mass under general anesthesia with number 6 endotracheal tube. The worm like mass (Fig. 3) was excised with cautery from right side of the laryngeal surface of the epiglottis. The mass was sent for histopathological examination (Fig. 4) which revealed, hyperplastic stratified squamous epithelium, smooth muscle bundle zone, seromucinous gland zone, along with duct and vascular zone, suggestive of hamartomatous polyp. The immediate postoperative period was uneventful. At the first postoperative visit, 1 week after surgery, the patient's symptoms had resolved. The surgical site had healed. There has been no evidence of recurrent lesion till the last follow-up of 3 years.

\section{DISCUSSION}

Hamartomas are benign lesions, most commonly found in the lungs, kidneys and intestine. Although they are rarely seen in head and neck, they can develop in nasopharynx, nasal cavity, eustachian tube, tongue, oropharynx, hypopharynx, larynx, cervical esophagus and trachea. ${ }^{6,7}$ 


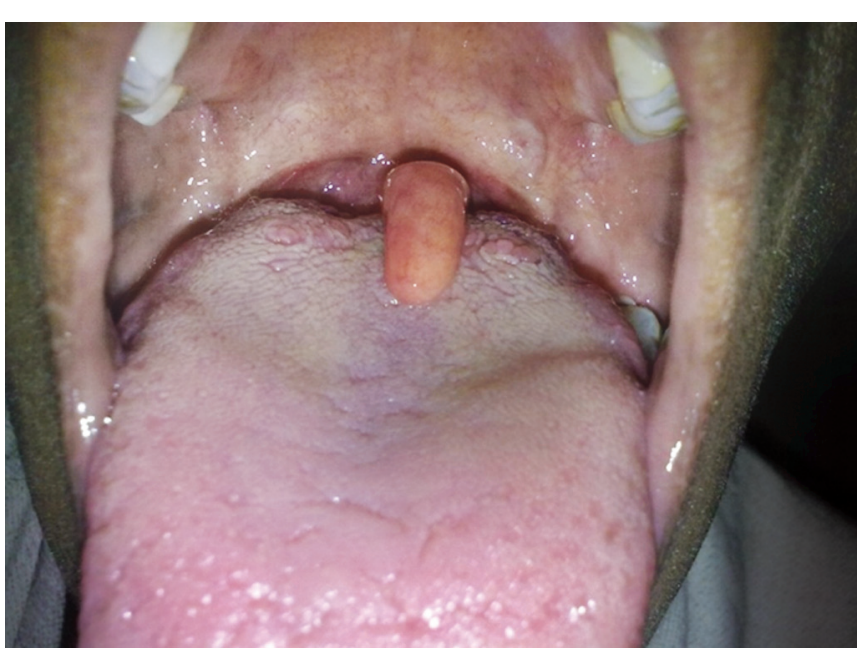

Fig. 1: Worm-like mass in oral cavity

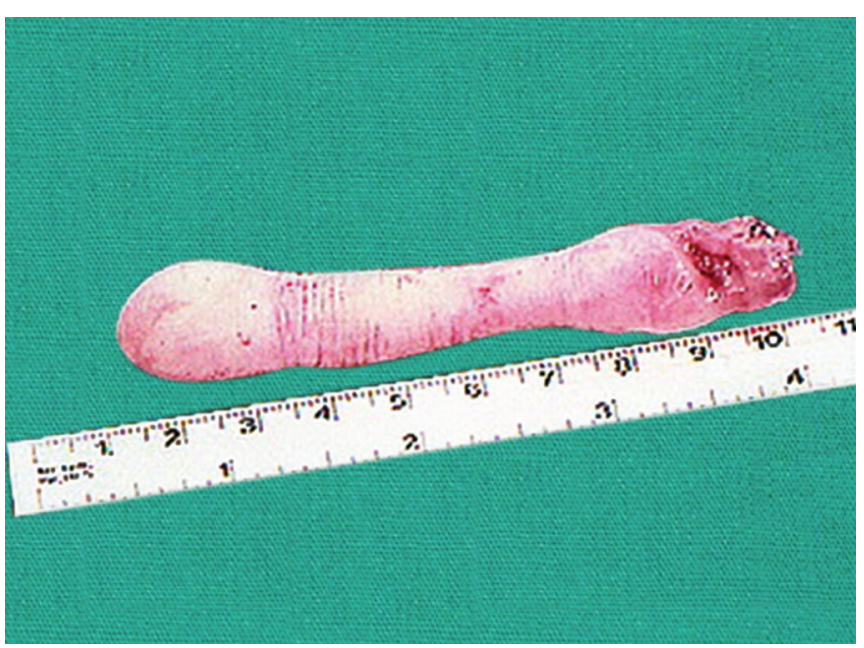

Fig. 3: Tumor resected en bloc hamartomatous polyp

The pathophysiologic mechanism underlying the origin of laryngeal hamartomatous polyps is unknown. In this case, the origin of the hamartomatous polyp from laryngeal surface of epiglottis cannot be explained by muscular weakness. ${ }^{8}$ Nonetheless, a small mucosal lesion in that region exposed to the pressure changes associated with deglutition and innumerable boluses of swallowed material could provide a nidus for the formation of a giant hamartomatous polyp.

The first report of a laryngeal hamartoma was published by Climie et $\mathrm{al}^{9}$ in 1963. Zapf et $\mathrm{al}^{10}$ in 1981, described a supraglottic polypoid lesion in a 6 -week-old child that caused increasing stridor and sternal retraction. In infants, laryngeal hamartomas are typically associated with severe laryngeal obstruction. ${ }^{10-12}$ In adults, the signs and symptoms of laryngeal hamartomas are more diverse. Some adults experience hoarseness, dyspnea, and even an acute airway obstruction that may require tracheotomy. ${ }^{7,13}$ Other adults experience a longstand-

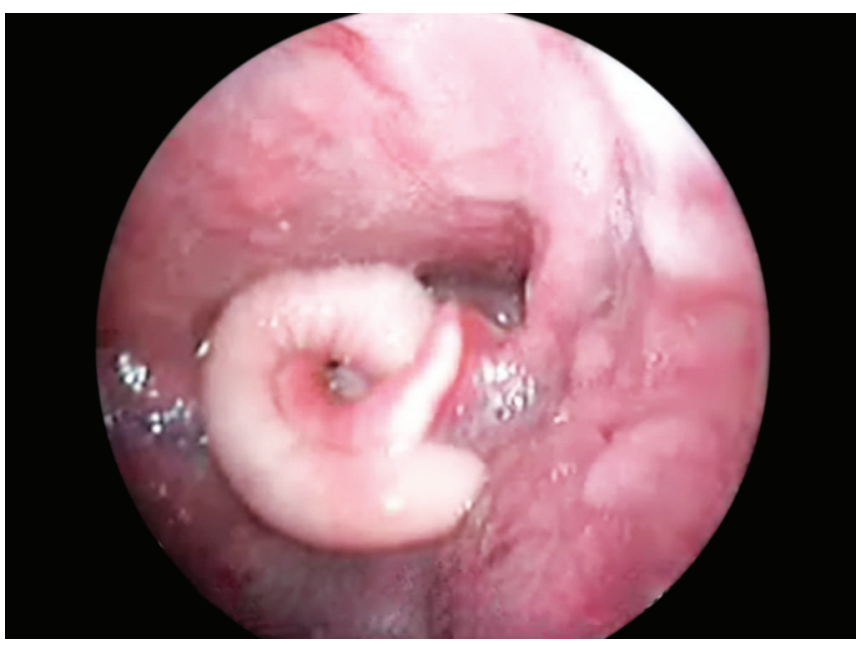

Fig. 2: Preoperative videolaryngoscopy

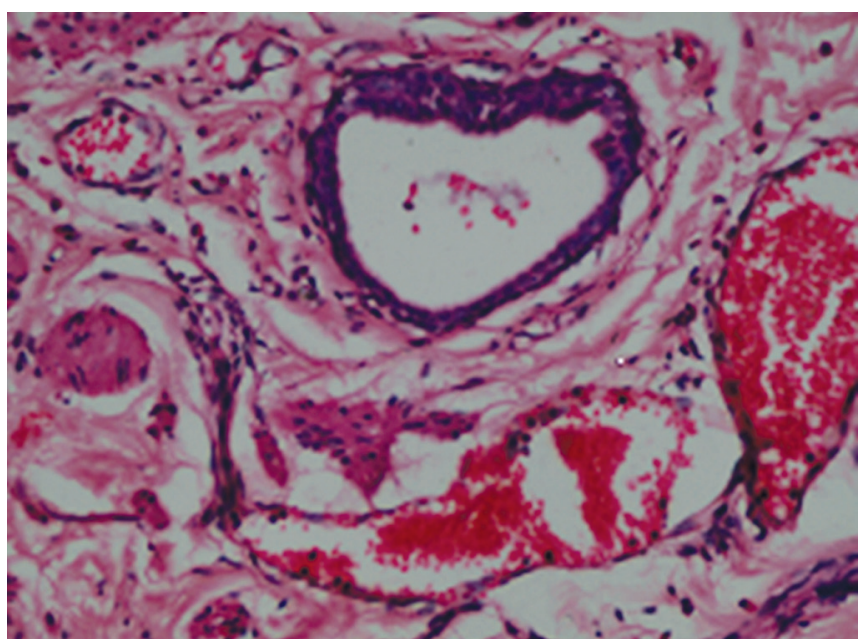

Fig. 4: HPE showed a central core of dilated vascular spaces surrounded by a matrix of fibrous connective and adipose tissue covered by normal squamous epithelium, with no evidence of hyperplastic or dysplastic changes

ing and sometimes nearly asymptomatic course of disease. ${ }^{9}$ Our patient did not notice any laryngeal symptoms for many years of onset, despite her slight but noticeable hoarseness to the examiner. Patient noticed recurrent episodes of dyspnea and choking sensation prior to admission after prolonged asymptomatic period.

Any laryngeal tumor has to be investigated by video laryngoscopy and computed tomography scan to assess the extent of the tumor. ${ }^{14}$ Although it has been shown that most laryngeal hamartomas develop in the supraglottic region as in our case, retrolaryngeal tumor growth and coincidence with laryngeal clefts ${ }^{15}$ has to be excluded by meticulous endoscopy of the larynx and hypopharynx. Final diagnosis is based on histopathological examination. If the diagnosis is established, total resection of the lesion is the treatment of choice. In present case, on video laryngoscopy, a smooth, shiny elongated pinkish worm like mass with base attached to the 
right laryngeal surface of the epiglottis with freely moving at other end was noted.

The mass was subjected for total excision under general anesthesia with endoscopic assisted cautery and sent for frozen section which revealed hamartomatous polyp. Postoperative period was uneventful and there was no recurrence of tumor after 3 years of follow-up. If the lesion is well-encapsulated and of small size on presentation, endoscopic removal using a $\mathrm{CO}_{2}$ laser/cautery, either alone ${ }^{16}$ or in combination with microscopic instrument, ${ }^{17}$ is adequate. Zapf et al ${ }^{10}$ debulked a supraglottic polypoid lesion with a snare through a rigid endoscope. Postoperative complications after endoscopic surgery (i.e. immediate massive hemorrhage) have been reported. ${ }^{18}$ An open approach should be indicated for larger tumor. ${ }^{5,10}$ A transpharyngeal approach will expose retrolaryngeal extent of tumor growth.

\section{CONCLUSION}

Our case is rare variety of presentation in view of long history of nontroubling foreign body sensation in the throat with recent history of breathing difficulty and worm like mass in the throat. When symptoms are vague, laryngeal hamartomas may be misdiagnosed as a psychiatric disorder.

\section{REFERENCES}

1. Albrecht EU. Hamartome. Verh Dtsch Ges Pathol 1904;7: 153-157.

2. Wenig BM, Heffner DK. Respiratory epithelial adenomatoid hamartomas of the sinonasal tract and nasopharynx: a clinicopathologic study of 31 cases. Ann Otol Rhinol Laryngol 1995; 104(8):639-645.

3. Barax CN, Lebwohl M, Phelps RG. Multiple hamartoma syndrome. J Am Acad Dermatol 1987;17(2):342-346.
4. García-Lliberós A, Gomez MJ, Armengot-Carceller M. Rare sinonasal and laryngeal manifestations of Cowden's disease. Otolaryngol Head Neck Surg 2013;149(3):513-514.

5. Archer SM, Crockett DM, McGill TJ. Hamartoma of the larynx: report of two cases and review of the literature. Int J Pediatr Otorhinolaryngol 1988;16(3):237-243.

6. Patterson HC, Dickerson GR, Pilsh BZ, Bentkover SH. Hamartoma of the hypopharynx. Arch Otolaryngol 1981;107(12): 767-772.

7. Evans KL, Lowe DG, Keene MH. Vallecula angioleiomyoma: unusual cause of acute adult airway obstruction. J Laryngol Otol 1990;104(4):341-343.

8. Borges A, Bikhazi H, Wensel JP. Giant fibrovascular polyp of the oropharynx. Am J Neuroradiol 1999;20(10):1979-1982.

9. Climie ARW, Waggoner LG, Krabbenhoft KL. Lymphoid hamartoma of the larynx. Laryngoscope 1963;74(10):1381-1388.

10. Zapf B, Lehmann WB, Snyder GG 3rd. Hamartoma of the larynx: an unusual cause for stridor in an infant. Otolaryngol Head Neck Surg 1981;89(5):797-799.

11. Cohen SR. Posterior cleft larynx associated with hamartoma. Ann Otol Rhinol Laryngol 1984;93(5):443-446.

12. Kşlal FM, Acar M, Acar B, Karahan F. Laryngeal fibrous hamartoma presenting with airway obstruction at birth. J Craniofac Surg 2013;24(4):e383-e384.

13. Cenik Z, Uyar Y, Ozer B, Gungor S, Bulun E. An unusual laryngeal hamartoma: Lipofibroleiomyoma. J Otolaryngol 1993;22(2): 136-137.

14. Windfuhr JP. Laryngeal hamartoma. Acta Otolaryngol 2004;124(3):301-308.

15. Lyons TJ, Variend S. Posterior cleft larynx associated with hamartoma. J Laryngol Otol 1988;102(5):471-472.

16. Linder A. Hamartoma of the larynx causing neonatal respiratory distress. J Laryngol Otol 1997;111(2):166-168.

17. Fine ED, Dahmas B, Arnold JE. Laryngeal hamartoma: a rare congenital abnormality. Ann Otol Rhinol Laryngol 1995;104(2):87-89.

18. Hosal AS, Hosal IN, Gungen Y, Onerci M. Hamartoma of the larynx: a case of unusual bleeding after microlaryngoscopy. Ear Nose Throat J 1998;77(11):910-913. 